\title{
Executive Function Impairments in Patients with Depression
}

\author{
Mariana R.P. Alves ${ }^{1}$, Tetsuya Yamamoto ${ }^{2,3}$, Oscar Arias-Carrión ${ }^{4}$, Nuno B.F. Rocha ${ }^{5}$, Antonio E. \\ Nardi $^{1}$, Sergio Machado ${ }^{1,6}$ and Adriana Cardoso ${ }^{1}$
}

\author{
${ }^{I}$ Panic and Respiration, Institute of Psychiatry of Federal University of Rio de Janeiro, Brazil; National Institute for \\ Translational Medicine (INCT-TM), Brazil \\ ${ }^{2}$ Institute of Biomedical \& Health Sciences, Hiroshima University, Hiroshima, Japan \\ ${ }^{3}$ The Japan Society for the Promotion of Science, Japan \\ ${ }^{4}$ Unidad de Trastornos del Movimiento y Sueño, Hospital General Dr. Manuel Gea González, Secretaria de Salud \\ México DF, México \\ ${ }^{5}$ Polytechnic Institute of Porto, School of Allied Health Sciences, Porto, Portugal \\ ${ }^{6}$ Physical Activity Neuroscience, Physical Activity Sciences Postgraduate Program - Salgado de Oliveira University, \\ Niterói, Brazil
}

\begin{abstract}
Depression, the most prevalent psychiatric disorder, has a lifelong risk of $20 \%$ and is related to high rates of death among the patients. Thus, this study aims to conduct a systematic review of changes in executive functions of adult patients diagnosed with depression. We found 1381 articles; however, only 28 were selected and recovered. The inclusion criteria was the assessment of executive functions with at least one neuropsychological test, and articles that evaluated primarily adult individuals with depression, without comparison to other psychiatric disorders. Although most of the studies ( 25 out of 28 analyzed) have shown deficits in some executive subcomponents, these findings are not conclusive because they used different parameters of assessment. Moreover, many variables were not controlled, such as the different subtypes of the disorder, the high level of severity, comorbidity and the use of drugs. Most studies showed different deficits in executive functions in depressed patients, but further longitudinal studies are needed in order to confirm these findings.
\end{abstract}

Keywords: Cognitive impairment, depression, drugs, executive functions, neuropsychological assessment, psychiatric disorders.

\section{INTRODUCTION}

Depression, the most prevalent psychiatric disorder, has a lifelong risk of $20 \%$ and is related to high rates of death among the patients [1]. Data from the World Health Organization (WHO) showed that depression is among the ten medical disorders that cause greater disability, due to not only the psychological frame, but to the risk of developing other diseases, such as diabetes and coronary diseases $[1,2]$. This is neither the only nor the main reason that leads depression to impact the patients' lives: their manifestation can also worsen the prognostic of medical treatment which, due to physical, cognitive and quality of life impacts as a result of depression, can lead to avoidance/ deprivation of medical services [2].

Other important point is that most patients experience more than one episode of depression throughout life, and the chance of recurrence increases if the first episode occurred early in their lives and if there is a family history of disorder.

Additionally, new episodes, stress and the duration of untreated illness influence the prognosis [1].

Depression also features a large heterogeneity regarding its clinical aspects depending on the timing of their manifestation (childhood, young adulthood, midlife, and elderhood), and this difference reflects a differential pathway to illness. In the case of younger patients changes in anxiety, sleep, appetite and energy are perceived [3].

\section{NEUROBIOLOGY OF DEPRESSION}

Concerning the psychobiological model of depression, animal and human studies have shown that this is an integrative model, with changes in various fields that interact with each other. For example, decrease in monoamine neurotransmission, low BDNF concentration, raised cytokines, dysregulation of the HPA axis, changes in cortical and subcortical brain areas and variations in genetic aspects [1].

Regarding the neurobiological aspects, research has advanced greatly because of different neuroimaging techniques, such as magnetic resonance imaging (MRI), positron emission tomography (PET) and functional MRI (fMRI). The brain areas involved include the limbic system (especially the amygdala and the hippocampus) and the 
prefrontal cortex (PFC). Changes in the activity of these areas are considered central to the pathophysiology of depression [1]. Thus, three regions seem to play a crucial role in the depression: the orbitofrontal cortex (OFC), the dorsolateral prefrontal cortex (DLPFC) and the anterior cingulated cortex (ACC) [3].

The PFC has an integrative function, since it gathers sensorimotor, motivational and affective information. This region can be subdivided into lateral (posterior dorsolateral, mid-dorsolateral, ventrolateral), orbitofrontal, ventromedial, basal, orbital, frontopolar, anterior and rostral [4]. Dorsolateral and ventromedial are connected with the cingulate gyrus and the hippocampus. Each one has different assignments and, possible dysfunctions have different roles in the maintenance of the psychopathology of depression [1]. The Amygdala is related to the selection and coordination of cortical and neuroendocrine responses, and emotional learning and memory. Therefore, abnormal activations of these regions have been related to the severity of depression [1]. Hippocampus is a brain structure that has been most studied in relation to depression, both in animals and humans, for several reasons, such as its association with learning, memory, emotional dependence and high capacity for neuroplasticity [1].

Specific studies of a neurobiological model of depression helped to develop a theoretical structure that can offer preventive interventions and better understanding of the possible cognitive functioning of these patients [3].

\section{Neuropsychology of Depression}

Neuropsychological assessment has been an important tool for assessing psychiatric disorders, since its findings allow an association between the behavioural and functional data of the patient and the neuroanatomical and neurophysiological findings [5]. Studies have shown that mood changes not only the areas, but also the process by which the thought occurs. Thus, in addition to clinical symptoms, depression may be accompanied by cognitive deficits, such as alterations in perception, attention, memory, processing speed, processing emotionally and, particularly, executive functions [6].

\section{Executive Functions}

Executive function is a term that comprises a set of cognitive processes [7]. Its first report was made by Luria, and although he has not used this term, he described a series of disorders related to executive dysfunctions, for instance, conduct problems, due to frontal lesions [8, 9]. Such understanding was improved, until we get to one of the most popular definitions of executive functions from Lesak, who defined the executive functions as the ability to formulate goals, plan and perform effectively $[10,11]$. Therefore, it is an essential capability to make individuals independent, creative and socially integrated [12].

Executive functions are commonly associated with deficits from lesions in frontal regions and some psychiatric disorders, such as depression, which present marked frontal dysfunctions. These dysfunctions are so important to the patient's independence, that it becomes necessary to evaluate and better understand their possible effects in this psychopathology [7]. The studies that have begun to correlate depression and deficits in executive functions involved psychometrics and neuroimaging, and showed deficits in several aspects, such as abstraction ability, problem solving, loss of cognitive flexibility and tendency to perseverate [13].

Thus, this study aimed to conduct a systematic review of changes in executive functions of adult patients diagnosed with depression.

\section{METHODS}

A systematic search was conducted using the PubMed, ISI Web of Knowledge and PsycInfo databases using the following terms: "neuropsychological assessment", "depression" and "executive functions". The survey was conducted in February 2013; there was no time restriction given for any database.

A total of 1381 references were found (882 in Pubmed; 276 in ISI Web of Science; and 223 in PsycInfo). 65 of these articles were in a language other than English and 229 were duplicates; these were, therefore, excluded. Remained for abstract analysis 1087 references, and 28 articles were selected and recovered (see Fig. 1). Only articles using at least one neuropsychological test for executive functions, evaluating only adult subjects and focusing on individuals with depression (without comparison to another psychiatric disorder) were selected. These exclusion criteria were necessary because of the extensive material in the literature, and also to focus the study only in patients with depression.

\section{RESULTS}

In neuropsychological assessment researches with adult patients with depression, many instruments are used and different functions are assessed. However, this study will rise only the findings related to executive functions in each of the studies (Table 1).

\section{Executive Functions in Adults with Depression}

One study recruited 40 subjects with Major Depressive Disorder (MDD) and divided them into 2 subgroups: one with 20 subjects that have a history of 1 or 2 depressive episodes (mild group) with a mean age of 44.40 years and another subgroup of 20 subjects with a history of three or more depressive episodes (severe group) with a mean age of 48.15. There was also a group of 20 control subjects matched by age and education to the total group of 40 subjects with depression (before subdivision), with a mean age of 41.15 years. The Behavioural Assessment of the Dysexecutive Syndrome Q (BADS) was used to analyze task management, planning and monitoring, in order to assess executive functions. Two subtests of German word fluency task (RWT) were used to obtain cognitive flexibility related information; and visual and spatial backward memory span were also assessed by the Wechsler Memory Scale Revised (WMS-R) in order to measure sequenced coding. The results demonstrated that the control group showed better results than both patients' groups on all tests $\mathrm{F}(3,55)=11.74$; $\mathrm{p}<0.001$. And there is a relation between the severity of the disorder and worse performance. The findings showed that 


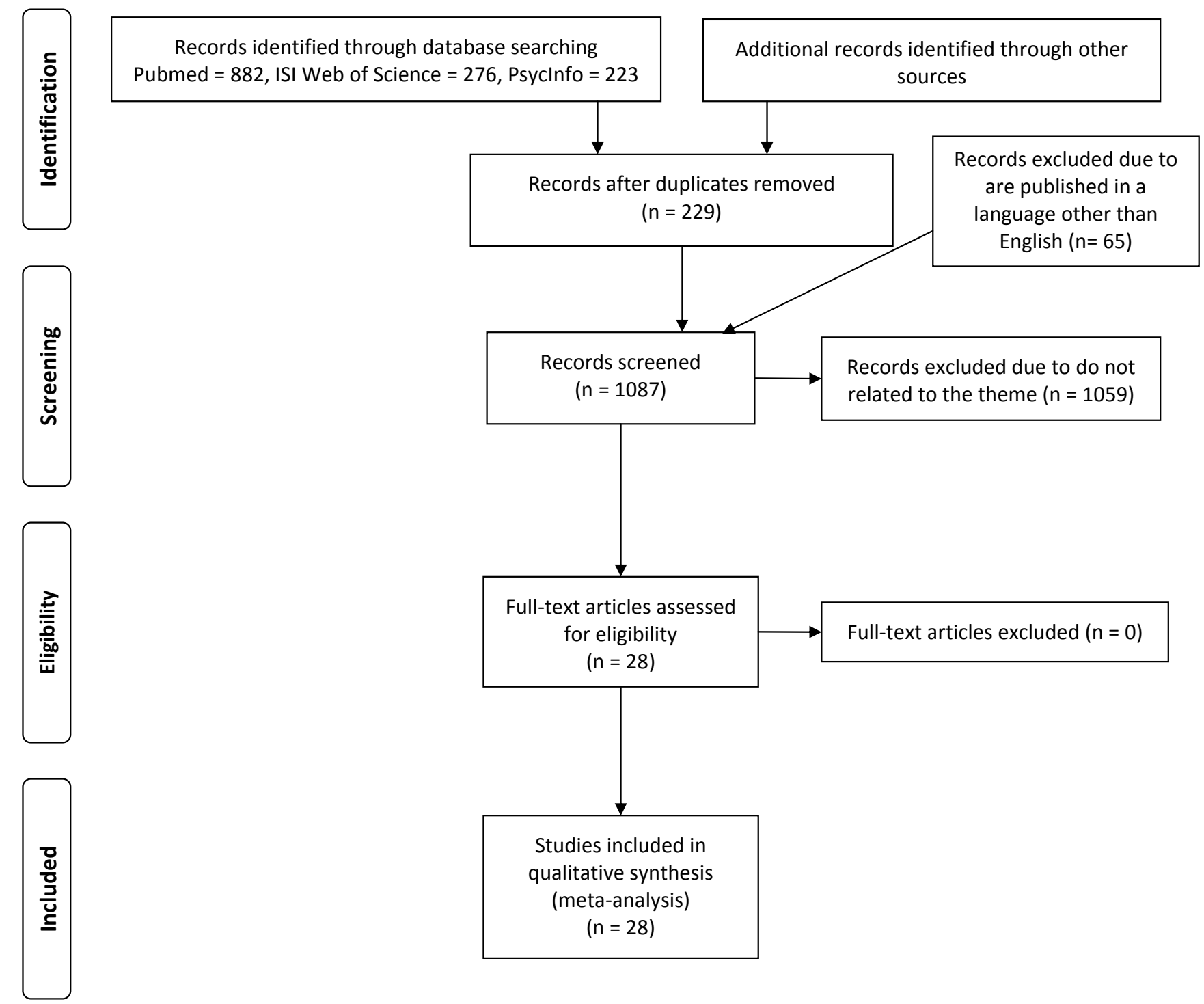

Fig. (1). Results of search strategy related to depression in elderly.

especially in the BADS test and backward memory span these differences were clearer $F(3,55)=3.22 ; p=0.03$ [14].

Another study conducted by neuropsychological evaluation in 123 patients with mild to moderate nonbipolar MDD without psychotic features and average age of 39.0 years in comparison to a control group of 36 subjects matched by age, gender and average age of 40.2 years old. The assessment of executive functions used four measures: 1) the Halstead-Reitan Categories Test of concept formation; 2) the Controlled Oral Word Association Test (COWAT); 3) the Wisconsin Card Sort Test (WCST), 4) the Trail Making Test Part B (TMT B). In addition, the Cambridge Neuropsychological Test Automated Battery (CANTAB) was used, combining a series of computerized tests that assess different functions, among which the executive functions, presented on a high-resolution touch-screen monitor. The results reveal that patients exhibit impairment on the WCST performance on various parameters, such as number of categories completed $\mathrm{t}=2.24 ; \mathrm{p}=.03$, perseverative responses $\mathrm{t}=2.39 ; \mathrm{p}=.02$, perseverative errors $\mathrm{t}=2.23 ; \mathrm{p}=.03$, and failures to maintain set $\mathrm{t}=2.01 ; \mathrm{p}=.05$. However, such deficits were not observed in the other three tests applied (Categories, Verbal Fluency and Trail B), as well as the CANTAB in their executive measures. The deficits found from the WCST suggest impairment in the ability to generate and maintain problem-solving strategies and setshifting ability. The authors suggest that the difference from this to other studies who often find deficits in other tests may be related to the severity of the disorder in these other patients [15].

One study compared 20 patients diagnosed with MDD and average age of 41.35 years with 20 subjects of a control group with average age of 38.4 years matched by gender and number of years of education. The authors want to assess the mechanisms of cognitive inhibitory facing emotional and neutral stimulus. For the evaluation of frontal executive functions the following tests were used: Modified six elements test, Brixton Spatial Anticipation Test, Dual-task 
Table 1. Summary of the studies related to depression in elderly.

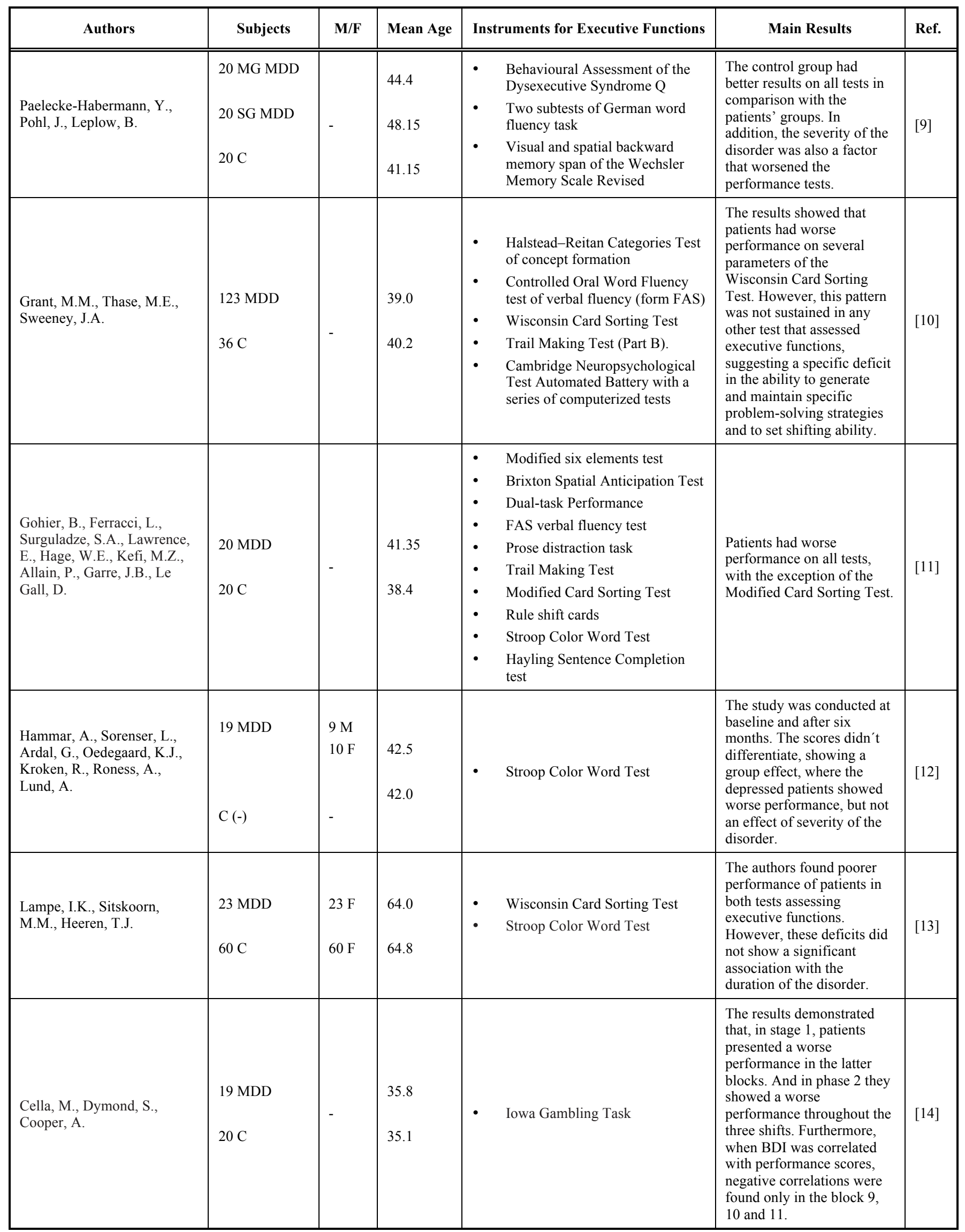




\begin{tabular}{|c|c|c|c|c|c|c|}
\hline Authors & Subjects & $\mathbf{M} / \mathbf{F}$ & Mean Age & Instruments for Executive Functions & Main Results & Ref. \\
\hline $\begin{array}{l}\text { Gualtieri, C.T., Johnson, } \\
\text { L.G., Benedict, K.B. }\end{array}$ & $\begin{array}{l}38 \mathrm{MDD} \\
31 \mathrm{MDD} \text { AM } \\
69 \mathrm{C}\end{array}$ & $\begin{array}{l}18 \mathrm{M} \\
20 \mathrm{~F} \\
9 \mathrm{M} \\
22 \mathrm{~F} \\
\\
25 \mathrm{M} \\
44 \mathrm{~F}\end{array}$ & $\begin{array}{l}43.55 \\
41.30\end{array}$ & $\begin{array}{ll}\text { - } & \text { Stroop Color Word Test } \\
\text { - } & \text { Shifting attention test }\end{array}$ & $\begin{array}{l}\text { The results showed the } \\
\text { control group performed } \\
\text { best in most of the variables } \\
\text { assessed, followed by the } \\
\text { group of depressed patients } \\
\text { treated with antidepressants } \\
\text { and, finally, by the } \\
\text { depressed patients without } \\
\text { any medication. }\end{array}$ & [15] \\
\hline $\begin{array}{l}\text { Porter, R.J., Gallagher, P., } \\
\text { Thompson, J.M., Young, } \\
\text { A.H. }\end{array}$ & $\begin{array}{l}44 \mathrm{MDD} \\
44 \mathrm{C}\end{array}$ & $\begin{array}{l}15 \mathrm{M} \\
29 \mathrm{~F} \\
15 \mathrm{M} \\
29 \mathrm{~F}\end{array}$ & 32.9 & $\begin{array}{ll}\text { - } & \text { Controlled oral word association } \\
\text { test } \\
\text { - } & \text { 'Exclude letter' fluency test } \\
\text { - } & \text { Vigil continuous performance } \\
\text { test } \\
\text { - } & \text { Spatial working memory } \\
\text { (CANTAB) } \\
\text { - } & \text { Tower of London (CANTAB). }\end{array}$ & $\begin{array}{l}\text { The results showed poorer } \\
\text { performance in patients } \\
\text { with depression in } \\
\text { comparison with the control } \\
\text { group. }\end{array}$ & [16] \\
\hline $\begin{array}{l}\text { Crews Jr., W.D., Harrison, } \\
\text { D.W., Rhodes, R.D. }\end{array}$ & $\begin{array}{l}30 \mathrm{MDD} \\
30 \mathrm{C}\end{array}$ & $\begin{array}{l}30 \mathrm{~F} \\
30 \mathrm{~F}\end{array}$ & $\begin{array}{l}20.33 \\
20.20\end{array}$ & $\begin{array}{ll}\text { - } & \text { Design Fluency Test } \\
\text { - } & \text { Hand Dynamometer Tests of } \\
\text { Grip Strength, Perseveration and } \\
\text { Fatigue } \\
\text { - } & \text { FAS Test } \\
\text { - } & \text { Stroop Color Word Test } \\
\text { - } & \text { Trail Making Test (Parts A and } \\
\text { B) }\end{array}$ & $\begin{array}{l}\text { The results did not show } \\
\text { significant differences } \\
\text { between groups in any of } \\
\text { the tests that assessed } \\
\text { executive functions. }\end{array}$ & [17] \\
\hline $\begin{array}{l}\text { Langenecker, S.A., } \\
\text { Bieliauskas, L.A., Rapport, } \\
\text { L.J., Zubieta, J.K., Wilde, } \\
\text { E.A., Berent, S. }\end{array}$ & $\begin{array}{l}21 \mathrm{MDD} \\
20 \mathrm{C}\end{array}$ & $\begin{array}{l}21 \mathrm{~F} \\
20 \mathrm{~F}\end{array}$ & $\begin{array}{l}32.2 \\
29.5\end{array}$ & - $\quad$ Modified Go / No-go test & $\begin{array}{l}\text { Significant differences were } \\
\text { found between groups in the } \\
\text { test, as well as a significant } \\
\text { interaction between the } \\
\text { group and the performance } \\
\text { in the task. }\end{array}$ & [18] \\
\hline $\begin{array}{l}\text { Degl'Innocenti, A., Agren, } \\
\text { H., Bäckman, L. }\end{array}$ & $17 \mathrm{C}$ & $\begin{array}{l}8 \mathrm{M} \\
9 \mathrm{~F} \\
8 \mathrm{M} \\
9 \mathrm{~F}\end{array}$ & 49.0 & $\begin{array}{ll}\text { - } & \text { Controlled oral word association } \\
\text { test } \\
\text { - } & \text { Wisconsin Card Sorting Test } \\
\text { - } & \text { Stroop Color Word Test }\end{array}$ & $\begin{array}{l}\text { The results found } \\
\text { significant differences } \\
\text { between depressed patients } \\
\text { and the control group in all } \\
\text { tests. }\end{array}$ & [20] \\
\hline $\begin{array}{l}\text { Stordal, K.I., Lundervold, } \\
\text { A.J., Egeland, J., Mykletun, } \\
\text { A., Asbjornsen, A., Landro, } \\
\text { N.I., Roness, A., Rund, B.R., } \\
\text { Sundet, K., Oedegaard, K.J., } \\
\text { Lund, A. }\end{array}$ & $50 \mathrm{C}$ & $\begin{array}{l}18 \mathrm{M} \\
27 \mathrm{~F} \\
25 \mathrm{M} \\
25 \mathrm{~F}\end{array}$ & 35.56 & $\begin{array}{ll}\text { - } & \text { Controlled oral word association } \\
\text { test } \\
\text { - } & \text { Tower of London } \\
\text { - } & \text { Paced Auditory Serial Addition } \\
& \text { Test } \\
\text { - } & \text { Digits Backward } \\
\text { - } & \text { Stroop Color Word Test } \\
\text { - } & \text { Wisconsin Card Sorting Test }\end{array}$ & $\begin{array}{l}\text { The results showed } \\
\text { significant differences } \\
\text { between groups in all tests, } \\
\text { where patients with } \\
\text { depression performed } \\
\text { worse. However, the level } \\
\text { of commitment in each of } \\
\text { the tasks was variable. }\end{array}$ & [21] \\
\hline $\begin{array}{l}\text { Stordal, K.I, Lundervold, } \\
\text { A.J., Biringer, E., Egeland, J., } \\
\text { Hammar, A., Landro, N.I., } \\
\text { Roness, A., Rund, B.R., } \\
\text { Sundet, K., Lund, A. }\end{array}$ & $\begin{array}{l}43 \mathrm{MDD} \\
50 \mathrm{C}\end{array}$ & - & $\begin{array}{l}35.2 \\
32.9\end{array}$ & $\begin{array}{ll}\text { - } & \text { Paced Auditory Serial Addition } \\
\text { - } & \text { Test } \\
\text { - } & \text { Digit Backward subtest } \\
& \text { Controlled oral word association } \\
\text { - } & \text { test } \\
\text { - } & \text { Wisconsin Card Sorting Test } \\
\text { Stroop Color Word Test }\end{array}$ & $\begin{array}{l}\text { The results found } \\
\text { significant differences in all } \\
\text { measurements: set- } \\
\text { maintenance, inhibition, } \\
\text { working memory and verbal } \\
\text { fluency. Depressed patients } \\
\text { exhibited the worst } \\
\text { performance. }\end{array}$ & [22] \\
\hline
\end{tabular}




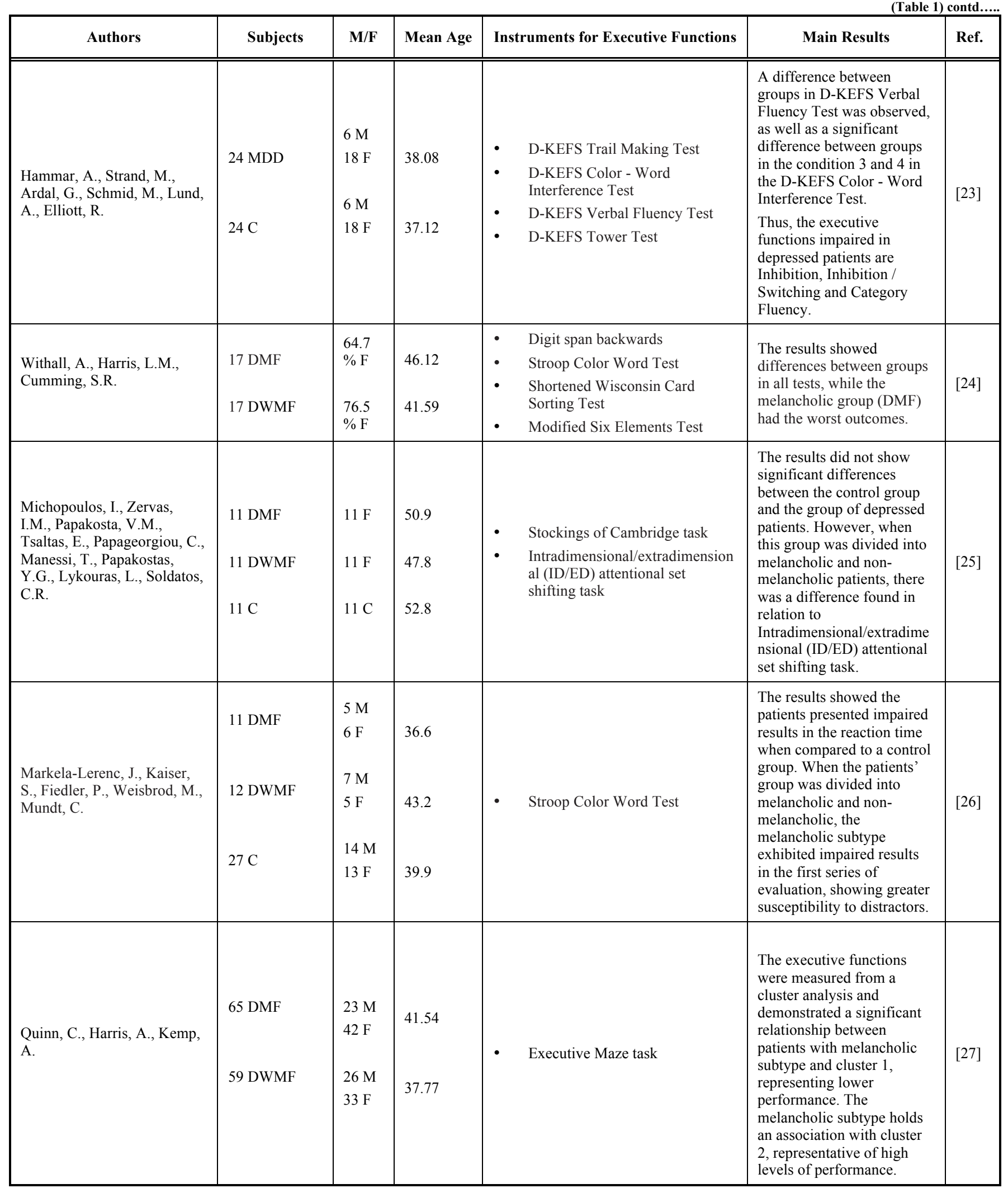




\begin{tabular}{|c|c|c|c|c|c|c|}
\hline Authors & Subjects & $\mathbf{M} / \mathbf{F}$ & Mean Age & Instruments for Executive Functions & Main Results & Ref. \\
\hline $\begin{array}{l}\text { Bhardwaj, A., Wilkinson, P., } \\
\text { Srivastava, C., Sharma, M. }\end{array}$ & $\begin{array}{l}20 \mathrm{R} \text { MDD } \\
20 \mathrm{C}\end{array}$ & $\begin{array}{l}18 \mathrm{M} \\
2 \mathrm{~F} \\
17 \mathrm{M} \\
3 \mathrm{~F}\end{array}$ & $\begin{array}{l}34.3 \\
33.0\end{array}$ & - Wisconsin Card Sorting Test & $\begin{array}{l}\text { Given the parameters } \\
\text { evaluated, patients showed } \\
\text { a worse performance in } \\
\text { three aspects: greater } \\
\text { number of nonperseverative } \\
\text { errors, fewer categories } \\
\text { completed and greater } \\
\text { number of trials required to } \\
\text { complete the test. }\end{array}$ & [28] \\
\hline Yamamoto, T., Shimada, H. & $\begin{array}{l}12 \mathrm{MDD} \\
11 \mathrm{P} \mathrm{MDD} \\
19 \mathrm{C}\end{array}$ & $\begin{array}{l}5 \mathrm{M} \\
7 \mathrm{~F} \\
2 \mathrm{M} \\
9 \mathrm{~F} \\
7 \mathrm{M} \\
12 \mathrm{~F}\end{array}$ & $\begin{array}{l}19.27 \\
19.79\end{array}$ & $\begin{array}{l}\text { - Behavioural Assessment of the } \\
\text { Dysexecutive Syndrome } \\
\text { - } \quad \text { Verbal Fluency Test. }\end{array}$ & $\begin{array}{l}\text { There were nOt found } \\
\text { significant differences } \\
\text { between the two patient } \\
\text { groups and the control } \\
\text { group. }\end{array}$ & [29] \\
\hline $\begin{array}{l}\text { Preiss, M., Kucerova, H., } \\
\text { Lukavsky, J., Stepankova, H., } \\
\text { Sos, P., Kawaciukova, R }\end{array}$ & $\begin{array}{l}97 \mathrm{R} \text { MDD } \\
97 \mathrm{C}\end{array}$ & $\begin{array}{l}46 \mathrm{M} \\
51 \mathrm{~F} \\
46 \mathrm{M} \\
51 \mathrm{~F}\end{array}$ & $\begin{array}{l}46.3 \\
46.1\end{array}$ & - $\quad$ Trail Making Test (part B) & $\begin{array}{l}\text { The results showed that the } \\
\text { cognitive flexibility } \\
\text { evaluated by the Trail } \\
\text { Making Test (Part B) was in } \\
\text { shortfall in patients. This } \\
\text { demonstrates that such } \\
\text { impairments remain even } \\
\text { after remission of the } \\
\text { disorder. }\end{array}$ & {$[30]$} \\
\hline $\begin{array}{l}\text { Hasselbalch, B.J., Knorr, U., } \\
\text { Hasselbalch, S.G., Gade, A., } \\
\text { Kessing, L.V. }\end{array}$ & $\begin{array}{l}88 \text { UDRS } \\
50 \mathrm{C}\end{array}$ & $\begin{array}{l}28 \mathrm{M} \\
60 \mathrm{~F} \\
15 \mathrm{M} \\
35 \mathrm{~F}\end{array}$ & $\begin{array}{r}59.8 \\
59.7\end{array}$ & $\begin{array}{ll}\text { - } & \text { Stroop Color Word Test } \\
\text { - } & \text { Wisconsin Card Sorting Test } \\
\text { - } & \text { Letter-Number Sequencing }\end{array}$ & $\begin{array}{l}\text { The patients performed } \\
\text { worse in all tests when } \\
\text { compared to the control } \\
\text { group. }\end{array}$ & [31] \\
\hline $\begin{array}{l}\text { Biringer, E., Lundervold, A., } \\
\text { Stordal, K., Mykletun, A., } \\
\text { Egeland, J., Bottlender, R., } \\
\text { Lund, A. }\end{array}$ & $30 \mathrm{MDD}$ & $\begin{array}{l}12 \mathrm{M} \\
18 \mathrm{M}\end{array}$ & 35.8 & $\begin{array}{l}\text { - Wisconsin Card Sorting Test } \\
\text { - Stroop Color Word Test }\end{array}$ & $\begin{array}{l}\text { The results showed that } \\
\text { recovery from depression } \\
\text { would be responsible for the } \\
\text { improvement of executive } \\
\text { functions scores in } 11 \% \text { of } \\
\text { cases. And the recovery } \\
\text { group showed no significant } \\
\text { difference compared to the } \\
\text { control group. }\end{array}$ & [33] \\
\hline $\begin{array}{l}\text { Withall, A., Harris, M., } \\
\text { Cumming, S.R. }\end{array}$ & $48 \mathrm{MDD}$ & $\begin{array}{l}66.7 \\
\% \mathrm{~F}\end{array}$ & 37.96 & $\begin{array}{ll}\text { - } & \text { Digit Span Backwards } \\
\text { - } & \text { Stroop Color Word Test } \\
\text { - } & \text { Shortened Wisconsin Card } \\
\text { - } & \text { Morting Test } \\
& \text { Modified Six Elements Test. }\end{array}$ & $\begin{array}{l}\text { The results showed that the } \\
\text { scores of perseverative } \\
\text { errors in Shortened } \\
\text { Wisconsin Card Sorting } \\
\text { Test were significant } \\
\text { predictors of the Hamilton } \\
\text { Depression Rating Scale in } \\
\text { the follow-up group. } \\
\text { However, this difference } \\
\text { was not sustained after the } \\
\text { Benjamini-Hochberg } \\
\text { correction. }\end{array}$ & {$[34]$} \\
\hline
\end{tabular}


(Table 1) contd....

\begin{tabular}{|c|c|c|c|c|c|c|}
\hline $\begin{array}{l}\text { Boeker, H., Schulze, J., } \\
\text { Richter, A., Nikisch, G., } \\
\text { Schuepbach, D., Grimm, S. }\end{array}$ & $\begin{array}{l}28 \mathrm{MDD} \\
28 \mathrm{C}\end{array}$ & $\begin{array}{l}15 \mathrm{M} \\
13 \mathrm{~F} \\
15 \mathrm{M} \\
13 \mathrm{~F}\end{array}$ & 35.03 & $\begin{array}{l}\text { - Intradimensional/ } \\
\text { extradimensional (ID/ED) } \\
\text { attentional set shifting task }\end{array}$ & $\begin{array}{l}\text { Impaired functioning was } \\
\text { detected in several variables } \\
\text { of the test applied. } \\
\text { However, there was no } \\
\text { significant difference } \\
\text { between subjects in the } \\
\text { acute phase of the disorder } \\
\text { and subjects in the } \\
\text { remission phase. }\end{array}$ & [35] \\
\hline $\begin{array}{l}\text { Westheide, J., Wagner, M., } \\
\text { Quednow, B.B., Hoppe, C., } \\
\text { Cooper-Mahkorn, D., Strater, } \\
\text { B., Maier, W., Kuhn, K.U. }\end{array}$ & $\begin{array}{l}15 \mathrm{MDD} \\
15 \mathrm{C}\end{array}$ & $\begin{array}{l}15 \mathrm{M} \\
15 \mathrm{M}\end{array}$ & $\begin{array}{l}45.1 \\
42.1\end{array}$ & $\begin{array}{ll}\text { - } & \text { Iowa Gambling Test } \\
\text { - } & \text { Go/No-Go Task } \\
\text { - } & \text { Delayed Alternation Task }\end{array}$ & $\begin{array}{l}\text { There were not found any } \\
\text { significant differences } \\
\text { between groups. }\end{array}$ & {$[36]$} \\
\hline
\end{tabular}

$\mathrm{C}=$ Healthy Control Subjects; DMF = Depression with melancholic features; DWMF: = Depression without melancholic features; MDD = Major Depressive Disorder; MG = Mild Group; MDDAM = Major Depressive Disorder with antidepressant monotherapy; PMDD = partially met the DSM-IV-TR criteria for MDD; RMDD = Recovered Major Depressive Disorder; SG = Severe Group; UDRS = Unipolar Disorder Remitted State; UD = Unipolar Depression.

Performance and FAS verbal fluency test - a French version of FAS task. As for the evaluation of inhibition, three subdivisions were made. Regarding the Access function, the instrument used was Prose distraction task. The evaluation of deletion function was made with TMT, The Modified Card Sorting Test and Rule shift cards. And the Restraint function was mensured with Stroop test and The Hayling Sentence Completion test. There were differences found between groups assessing the Modified six elements test, where patients had worse performance when compared to the control group $\mathrm{F}(1.38)=16.5 ; \mathrm{p}<.001$. They also showed poorer performance in the simple task of the dual-task performance $\mathrm{F}(1.38)=26.2 ; \mathrm{p}<.001$ and in the semantic aspect of the verbal fluency $\mathrm{F}(1.38)=32.6 ; \mathrm{p}<.001$. The results showed that, regarding the access of information, depressed patients read slower than the control group in all subtests of the Prose distraction task. And they also read significantly more semantic distractors (T2) than the control group $\mathrm{F}(1,38)=18.5 ; \mathrm{p}<.001$. Concerning the aspect of deletion function patients were slower to complete both parts of the TMT A, F(1,38)=37.9; $<<.001 ;$ Part B, F(1,38)=23.9; $\mathrm{p}<.001$. In relation to the rule shift cards they took more time to execute the task for the first rule, $F(1,38)=35.8 ; \mathrm{p}<.001$ and the second rule, $F(1,38)=79.3 ; p<.001$. However, no significant differences were found between patients and the control group in the Modified Card Sorting Test. In the assessing of the restraint function the time to execute the Stroop Test was significantly longer in the depressed group $\mathrm{F}(1,38)=148.8 ; \mathrm{p}<.001$, and was impaired in performance in the second part of the Hayling Sentence Completion Test, with longer time, $\mathrm{F}(1,38)=53.4 ; \mathrm{p}<.001$ and more errors, $\mathrm{F}(1,38)=13.2 ; \mathrm{p}<.001$. Thus, this study found deficits in all three aspects of inhibitory processing (access, deletion and restraint) in patients with depression [16]. These results confirm the hypothesis of a deficit in the anterior cingulate cortex in patients with depression, which leads to consequences in different cognitive functions such as error detection, anticipation of tasks, attention, motivation, and modulation of emotional responses [17].

A study using the Stroop paradigm evaluated 19 patients with recurrent unipolar MDD and average ages of 42.5 years, and compared them to a control group with a mean age of 42 years, matched by age, gender and level of education. Patients were evaluated at baseline along with the Hamilton
Depression Rating Scale (HDRS; scored > 18) and after 6 months, when most patients already had a reduction of the symptoms. Results showed a performance impairment in the patients in the two periods of evaluation, showing an effect in the group $\mathrm{F}(1,36)=7.51 ; \mathrm{p}<0.05 ; \mathrm{g} 2=0.18$ but no association to the severity/course of the disorder [18]. A comparative study was conducted including 23 female patients, aged between 46 and 82 years and diagnosed with recurrent MDD, and 60 healthy age-matched females aged between 45 and 85 years. The executive functions were assessed using the WCST and Stroop test. The results showed that patients had worse outcomes in the assessment of executive functions, when compared to the control group $\mathrm{F}(5.52)$; d.f. $=1.78 ; \mathrm{p}=0.021$. However, these deficits do not have a correlation with the duration of the disorder $r=-0.18$. Thus, the results suggest that the recurrence of depressive episodes is not one more aspect that affects executive functions in these patients [19].

Another study assessed the flexibility of decision-making in 19 patients with MDD and average age of 35.8 years and 20 healthy control subjects with a mean age of 35.1 years. For this evaluation the Iowa Gambling Task (IGT) was used, by a contingency-shift phase where decks progressively changed reward and punishment schedule. The results were obtained by subtracting the disadvantageous choices from the number of advantageous for each block of 20 trials. The results showed that in the first phase the control subjects were better at learning, especially in the latter blocks, with a significant main effect of group $F(1,37)=12.48$; $p=0.001$; and in phase 2 , controls showed better levels of learning throughout the three shifts $F(1,37)=11.37 ; p=0.002$. The tests conducted on phase two showed that control subjects perform better in blocks 7, 9, 10 and 11 (all $\mathrm{p}<0.05$ ). The results of this study can be correlated to the hypothesis that the orbitofrontal cortex has integrative function to signaling signals of reward/punishment for our actions and are able to detect and analyze details pertaining the overall situation [20]. To analyze the association between the severity of major depressive disorder and performance in the test, the authors examined the Beck Depression Inventory (BDI) scores in each of the blocks in this group. The results showed significant negative correlations in block $9 \mathrm{r}=-0.55 ; \mathrm{p}<0.05$, block $10 \mathrm{r}=-0.48 ; \mathrm{p}<0.05$ and block $11 \mathrm{r}=-0.62 ; \mathrm{p}<0.001$. Therefore, these results suggest that the worst performance 
in the three blocks of the test for patients with MDD would be due to alterations in sensitivity to reward and punishment by these patients [21].

One study recruited 38 subjects with unipolar nonpsychotic MDD without psychotropic drugs, 31 subjects with MDD treated with antidepressant monotherapy for at least four weeks and 69 subjects in the control group matched by age, race and gender. The neurocognitive evaluation was measured from the CNS Vital Signs, which is a computed battery composed of seven different tests that assess differents cognitive domains. With regard to the aspect of executive function evaluation, the corresponding tests were Stroop test and Shifting attention test. The results showed that there was a significant difference between the group with MDD without medication and the control group concerning the cognitive flexibility $\mathrm{t}=2.60 ; \mathrm{p}=0.01$. In fact, for most of the variables assessed the control group had the best scores, followed by patients with MDD treated with antidepressants and, finally, patients with MDD without medication [22].

Another study met 44 patients with a diagnosis of MDD all psychotropic medication-free for at least six weeks, with an average age of 32.9 years and a control group of 44 healthy subjects matched by age, gender, premorbid IQ, years of formal education and season of testing, with a mean age of 32.3 years. Furthermore, the women were matched by phase of menstrual cycle. For the evaluation of sustained attention and executive functions the following tests were used: COWAT, 'Exclude letter' fluency test, Vigil continuous performance test, Spatial working memory (CANTAB) and Tower of London (ToL - CANTAB). The results showed that patients with MDD issued fewer words in the Benton's FAS test $\mathrm{F}(4.48)$; d.f. $=1.86 ; \mathrm{p}=0.037$ and in the Exclude letter fluency $\mathrm{F}(8.75)$; d. $\mathrm{f}=1.84 ; \mathrm{p}=0.004$; had more errors of omission $\mathrm{U}=694.5 ; \mathrm{p}=0.04$ and commission $\mathrm{U}=684.5 ; \mathrm{p}=0.04$ in the Vigil continuous performance test, although there has been no difference between the groups regarding the time of latency $F(1.04)$; d.f. $=1,84 ; p=0.31$; in the Spatial working memory (CANTAB) they had more errors than the control group at $\operatorname{six} \mathrm{t}=2.91$; d.f. $=85 ; \mathrm{p}=0.005$ and eight shape of problems $\mathrm{t}=2.92$; d.f. $=85 ; \mathrm{p}=0.004$ and had a less efficient search strategy $\mathrm{F}(8.22)$; d.f.=1,85; $\mathrm{p}=0.005$; in ToL the only interaction obtained was initial thinking time $\mathrm{F}(3.88)$; d.f. $=3,225 ; \mathrm{p}=0.013$ [23].

A study conducted only with women, compared 30 women with depression and a mean age of 20.33 years to a control group of 30 women and a mean age of 20.20 years without depression, with approximate ages and intellectual levels to assess the executive functions of the two groups. Neuropsychological assessment was conducted based on the following tests: Design Fluency Test, Hand Dynamometer Tests of Grip Strength, Perseveration and Fatigue, FAS Test, Stroop Test, and the TMT A and B. Regarding the results, no significant differences were found between groups (depressed and non-depressed) in any of the tests, but the authors noted that these findings may have some relation with some points, such as depressed patients in the study are not hospitalized (which could worse their performance) [24].

Another study carried out only with women compared 21 women with MDD and a mean age of 32.2 years to 20 women in a healthy control group with a mean age of 29.5 years. The modified Go/No-go test of inhibitory control was performed in order to assess executive functions. The results showed that there was a significant difference between the groups in the test conducted $\mathrm{F}(1.36)=4.42 ; \mathrm{p}=.04$; eta' $=.111$, as well as a significant interaction between the group and the level in the task $\mathrm{F}(1.36)=4.11 ; \mathrm{p}=.05$; eta" $=.10$. These results allowed measuring problem solving and sustained effort in depressed women [25].

A study was conducted with 30 patients diagnosed with MDD and a mean age of 31.77 years and 30 subjects in a control group with a mean age of 31.47 years, matched by age, sex, and socio-economic status. Of the tests used, those who had measures of executive functions were the TMT B and the Digits Backward (DB). In the analysis of the results the authors divided the findings into four possibilities: if $p>0.05$, the difference was not significant, if $p<0.05$ the difference was significant, if $\mathrm{p}<0.01$ the difference was highly significant and if $p<0.001$ the difference was very highly significant. Regarding the comparison of performance between groups in the TMT B test the results were $p<0.001$, in other words, they were very highly significant. The comparison between groups in the DB test showed that $\mathrm{p}<0.05$, or simply, a significant difference. These results showed that patients with depression demonstrate deficits in the executive functions [26].

A study carried out with 17 patients with MDD and a mean age of 48.2 years and 17 subjects in a control group with a mean age of 49.0 years evaluated possible executive deficits resorting to COWAT, WCST and Stroop Test. The results found more favorable scores for the control group in all variables of the COWAT, $F(16.7) ; \quad M S E=150.2$; $\mathrm{p}<0,0001 ; \omega^{2}=0.3$, as well as the number of trials $\mathrm{F}(5,0)$; $\mathrm{MSE}=399.9 ; \mathrm{p}<0,005 ; \omega^{2}=0.1$, the number of errors, $\mathrm{F}(4.8)$; $\mathrm{MSE}=395.2 ; \quad \mathrm{p}<0,005 ; \omega^{2}=0.1$, the number of nonperseverative errors $\mathrm{F}(4.6)$; $\mathrm{MSE}=85.6 ; \mathrm{p}<0,005 ; \omega^{2}=0.1$, and the percentage of conceptual level responses $F(5.4)$; $\mathrm{MSE}=332.8 ; \mathrm{p}<0,005 ; \omega^{2}=0.1$, of the WCST. The Stroop Test also revealed a difference between groups, $\mathrm{F}(1,31)=9.7$; $\mathrm{MSE}=2037.7 ; \mathrm{p}<0.01 ; \omega^{2}=0.2$ and condition $\mathrm{F}(3,93)=73.2$; MSE $=173,3 ; \quad \mathrm{p}<0.0001 ; \quad \omega^{2}=0.7, \quad$ demonstrating that depressive patients also proved to be slower than the control group and to have a slower performance on incongruent trials under a baseline. Thus, this study showed that patients with major depression exhibit deficits in different domains of executive functions [27].

A study was conducted with 45 patients with MDD, recurrent and non-psychotic, and a mean age of 35.56 years. These patients were in a moderate to severe phase of the disorder and their depressive episodes varied between two and five. A control group was also included containing 50 subjects with a mean age of 32.92 years. The six tests that assessed executive functions were: COWAT, ToL, Paced Auditory Serial Addition Test (PASAT), DB from WAIS-R, Stroop Test and WCST. The results showed that patients performed worse on all tasks in comparison to the control group. Significant differences were found in phonemic and categorical verbal fluency, the PASAT, DB, Stroop Test, the failure to maintain set and perseverative errors from WCST. The level of commitment in each of the tasks was variable, being between -0.15 and -0.89 and the reliability analysis across all executive functions tests yielded an alpha value of 
0.827. The authors also calculated the total mean of executive function $\mathrm{z}$-score difference, which was estimated to $-2.15 \mathrm{~s}, 10=-0.22 \mathrm{~s}$ [28].

A study was conducted with 43 patients with a mean age of 35.2 years, diagnosed with recurrent moderate to severe MDD without psychotic features, with an average of 2 to 5 episodes of depression, and a control group consisting of 50 healthy subjects matched by age, gender, level of education and intellectual abilities, with a mean age of 32.9 years. The tests used for the evaluation of executive functions were: PASAT, DB from WAIS-R, COWAT, the Failure to Maintain Set variable from WCST and the Stoop Test. The measures of evaluation of the results were set-maintenance, inhibition, verbal fluency and working memory. The results found a significant difference between the groups in all measures used. However, the authors point out that despite such a significant difference exists there are patients without such deficits, as there are control groups/subjects with that feature, which shows that this variance can be explained by others factors than just the presence of the disorder. The authors found interactions between age and diagnosis as a way of predicting deficits executives, where patients with depression and older, have more chances of having such impairments $b$ value of $0.286 ; p</ 0.093$ in the linear regression model [29].

Another study compared 24 patients diagnosed with MDD and a mean age of 38.08 years and a control group of 24 healthy subjects matched by age, gender and years of education with a mean age of 37.12 years. For the neuropsychological tests the D-KEFS test battery was used. Concerning the executive functions, the D-KEFS Trail Making Test assesses the mental flexibility (setshifting) measured by condition 4, apart from other cognitive areas; The D-KEFS Color - Word Interference Test is a version of the Stroop paradigm and investigates the inhibitory capacity; The D-KEFS Verbal Fluency Test also assesses mental flexibility (set shifting) and The D-KEFS Tower Test is a version of ToL and assesses spatial planning, rule learning, and the ability to establish and maintain cognitive set. In the D-KEFS Color - Word Interference Test, there was a statistical difference between groups $\mathrm{F}(4,43)=3.81$; $\mathrm{p}=0.010$; Wilks' Lambda $=0.74$, partial eta-squared $=0.26$. In condition 3, which assessed inhibition, the patients took longer to complete the task $\mathrm{F}(1,46)=5,30 ; \mathrm{p}=0.026$, but there was no difference between groups in the number of errors. In condition 4 , which evaluated Inhibition/Switching, patients also took significantly more time to complete the task $\mathrm{F}(1,46)=5,49 ; \mathrm{p}=0.024$, but this didn't affect the number of errors found. As for D-KEFS Verbal Fluency, there were also found significant differences between groups $\mathrm{F}(3,44)=3.202 ; \mathrm{p}=0.032$; Wilks' Lambda $=0.82$, partial eta-squared $=0.18$. As for the D-KEFS Tower Test and D-KEFS Trail Making Test, no significant differences were found between groups. Thus, the executive aspects in which there were found impairments were Inhibition, Inhibition/Switch-ing and Category Fluency [30].

Executive Functions in Adults Presenting Melancholic and Non-Melancholic Subtypes of Major Depressive Disorder

One study recruited 34 patients diagnosed with MDD, 17 suffering from the melancholic subtype and 17 the nonmelancholic subtype. The authors sought to know if the differences of these subtypes explain the contradictory findings regarding the evaluation of cognitive functions in patients with depression. The group suffering from the melancholic subtype had a mean age of 46.12 years and the non-melancholic subtype group had a mean age of 41.59 years. For the evaluation of executive functions there were used the DB test, the Stroop Test, the Shortened WCST and the Modified Six Elements Test. There were differences between groups in all these tests, and the melancholic subtype group showed worse outcomes. The results were, $\mathrm{DB}, \mathrm{F}(1,29)=5.05 ;$ eta $2=0.15 ; \mathrm{p} \leq 0.05$, SCWT interference score $\mathrm{F}(1,29)=7.00$; eta $2=0.19 ; \mathrm{p} \leq 0.01$, WCST categories completed $\mathrm{F}(1,29)=13.63 ; \quad$ eta $2=0.32 ; \mathrm{p} \leq 0.001$, WCST perseverative errors $\mathrm{F}(1,29)=8.81$, eta $2=0.23, \mathrm{p} \leq 0.01$ and SET score $F(1,29)=8.94$; eta $2=024 ; p \leq 0.01$. Thus, the initial results and follow-up of 3 months proved consistent with other studies that showed executive deficits related to patients suffering from the melancholic subtype of depression [31].

Another study was conducted only with women. In total, 33 women participated, 11 diagnosed with depression with melancholic features and a mean age of 50.9 years, 11 with depression without melancholic features and a mean age of 47.8 years and 11 control subjects matched by sex, age and education with a mean age of 52.8 years. Patients with depression were admitted through the Women's Mental Health Program in Athens University Department of Psychiatry. Neuropsychological assessment was performed through a computerized battery. The assessment of executive functions was composed by the following tasks: the Stockings of Cambridge task (SOC) that accesses the ability of strategic planning of the subject; and the Intradimensional/extradimensional (ID/ED) attentional set shifting task, that accesses the maintainability of attention despite of the stimuli. The results showed that, although the control group obtained higher scores than the group of depressed patients, this difference was not significant. However, when patients were divided into melancholic and non-melancholic, there was a significant difference in the ID/ED task between the control group and the melancholic patients. In other tasks that assess frontal striatal functions no differences were found, which may be related to the small sample. Thus, these results show that set shifting deficits may be specific to the melancholic subtype of depression [32].

Another study selected 23 patients diagnosed with unipolar MDD and a mean age of 40 years, and a group of 27 healthy subjects matched by gender, age and year of school education and a mean age of 39.9 years. The patients group was divided into melancholic depression (11 subjects) with a mean age of 36.6 years and non melancholic (12 subjects) with a mean age of 43.2 years. The executive functions, particularly the inhibition of a learned routine, were assessed from a trial mixed manual version of the Stroop Test, presented in the Stim software (Neuroscan Inc.). The evaluation of the results was made from the software itself, with reaction time and errors data. When comparing the entire group of patients with depression to the control group, the only significant difference was the time of reaction, which revealed that patients have slower reaction time than the control group $F(1,48)=3.4 ; \mathrm{p}<0.07$. When the group of depressed patients were subdivided into melancholic and non melancholic, significant differences 
were found in the non melancholic group when compared to the control group $\mathrm{t}=-2.1 ; \mathrm{p}<0.05$, but only on the first series of evaluation. However, no significant differences were found between the control group and the melancholic subgroup in any of the four series performed. These findings suggest that non melancholic depressed patients would be more susceptible to distractors than melancholic depressed patients or healthy control subjects. However, the authors emphasize the importance of further studies, especially with a larger number of subjects [33].

A group of 124 patients with a primary diagnosis of MDD, 65 suffering from the melancholic subtype and a mean age of 41.54 years and 59 suffering from the non melancholic subtype and a mean age of 37.77 years were evaluated in order to verify the possible difference in neuropsychological profile among groups. Neuropsychological assessment was computerized and, in the executive functions case, the measure used was the Executive Maze task, which is a computerized adaptation of the Austin Maze. The analysis of the results was made by means of cluster because this measure has the ability to "identify groupings, patterns of attributes or categories that can be interpreted as a meaningful set by identifying how each category differs from the others". According to this analysis, cluster 1 would be indicated by lower performance on neuropsychological assessment and higher levels of severity and symptoms of the disorder, whereas cluster 2 is the opposite of 1 , indicating high levels of performance and low levels of severity and symptomatology. In the case of executive functions, higher scores indicate worse performance. A significant correlation was found between patients suffering from the melancholic and non melancholic subtypes and the measure of cluster $\mathrm{w}^{2}(1)=7.495 ; \mathrm{p}<.01$, where $58 \%$ of the melancholic subtype patients were associated to cluster 1 and $66 \%$ of non melancholic subtype patients were associated to cluster 2 [34].

\section{Executive Functions in Patients Recovering from Depression}

A study was conducted with a total of 20 patients recovering from depression with a mean age of 34.3 years and 20 control subjects matched by age group, sex and education, with a mean age of 33.0 years. The criteria of remission DSM IV was used, wherein remission occurred at least 2 months before. The WCST was used for the evaluation of executive functions, which found that the number of previous depressive episodes was significantly correlated with three parameters evaluated in this test, a greater number of non perseverative errors $(\mathrm{p}=0.02)$; fewer categories completed $(\mathrm{p}=0.03)$ and a greater number of trials required to complete the test $(\mathrm{p}=0.03)$. The problems with non perseverative errors may be related to the difficulty of strategy in problem-solving, and even to the control of the depressive symptoms (based on HDRS). This effect is not ceased, indicating it may be one more feature of the residual symptoms. Thus, there are two possibilities of explanation for this situation: greater vulnerability to depression in patients with impairment in executive functions; or consecutive episodes of depression would generate permanent damage in certain brain areas. However, there was no significant difference found regarding the perseverative errors, which can be related to the small sample size [35].

A study was conducted using three groups: the first consisted of 12 patients who had fully met the criteria for MDD (complete group) and have a mean age of 21.08 years; the second included 11 patients who had partially met the criteria (partial group) and have a mean age of 19.27 years; and the third consisted of 19 subjects in a control group with a mean age of 19.79 years. For the evaluation of executive functions the BADS, a battery composed of six subtests, and the Verbal Fluency Test were used. The results showed that the two groups composed of patients did not demonstrate a significant difference in both performance tests that assessed executive functions. These findings are different from those found in the literature, which stated that remitted MDD patients have executive dysfunctions. The authors explain these findings from different ages and duration of depressive episodes among the studies surveyed [36].

Another study also wanted to investigate the possible persistence of cognitive deficits despite the remission of depression. The study consisted of 97 patients in remission of MDD for at least 2 months with a mean age of 46.3 years, and 97 control subjects matched by age, education and gender, and mean age of 46.1 years. A valid Czech version of TMT B was used to assess executive functions, which is a test commonly used to evaluate cognitive flexibility. The results suggest impairment in cognitive flexibility in the group of patients Wilcoxon Matched Pairs Test, $\mathrm{n}=94$; $\mathrm{Z}=2.132 ; \mathrm{p}=0.033$, showing that cognitive deficits persist even in the remission of the disorder [37].

One study enrolled 88 patients with diagnosed with unipolar MDD in a remitted state with a mean age of 59.8 years, and 50 individuals in a control group matched by age and gender with a mean age of 59.7 years. The executive functions were assessed by three tests: the Stroop test, the WCST and the Letter-Number Sequencing, which is included in the Wechsler Adult Intelligence Scale, third edition (WAIS III). The TMT A and B was used as a marker of attentional and processing speed, but part B also requires cognitive flexibility and may also be classified as a test for executive functions. In the first test, the data taken into account was interference, the ability to inhibit automatic responses to controlled responses, then being associated with cognitive control and performance monitoring. And in the WCST case, the evaluation was based on the total number of errors. The results showed that patients performed worse on all tests in comparison with the control group [38].

Another study compared young and middle-aged patients with depression in its acute stage, six months after the remission of symptoms and six months after such remission. His goal was to clarify the specifics of cognitive dysfunction during the course of the disorder. The study consisted of 53 patients with a mean age of 43.5 years, 16 with a depressive episode and 37 with recurrent depression. Furthermore, there was a control group, with 13 subjects and a mean age of 46.4 years, with no history of Axis I psychiatric disorders, matched by age, gender and education. For the evaluation of executive functions there were used: Simple and alternate verbal fluency tasks, for the evaluation of cognitive flexibility; Raven Standard Progressive Matrices (SPM) to test visual problem solving; and three subtests of CANTAB, 
Delayed Matching to Sample Namely (DMS), (ID/ED) and Spatial Working Memory (SWM) for the evaluation of cognitive flexibility and working memory. The authors compared the cognitive deficits with variable remission of depression and found no significant data (all $p>0.05$ ). In other words, cognitive functions could not be regarded as a predictor of the course and remission of depression. Furthermore, patients with depression had inferior performance when compared with the control group [39].

A study tested 30 patients with a mean age of 35.8 years and diagnosis of recurrent unipolar MDD and retested the same about 2 years later when they were already partially or totally recovered from the disorder. The WCST and Stroop Test were used as measures for executive functions. The authors performed a correlation to find the association between the Hamilton Depression Rating Scale (HAM-D) and changes in executive functions. They found a positive Pearson's correlation coefficient $\mathrm{r}=0.33 ; \mathrm{p}=0.04$, one-tailed, and the depression recovery (measured through the HAM-D) explained $11 \%$ of the variance of EF improvement from T1 to $\mathrm{T} 2 \mathrm{r} 2=0.11$. Furthermore, the authors compared the results of the recovery group to a healthy group and there was not a significant group difference $\mathrm{p}=0.190$, two-tailed. These results showed that improvement in depressive symptoms is also accompanied by an improvement in measures of executive functions, so even long-term does not produce determinant cognitive impairment [40].

Another study evaluated 48 patients diagnosed with MDD and reassessed them 4 months later to check for possible changes in cognitive scores in case of remission of symptoms. The criteria of remission was based on an improvement of at least $50 \%$ of the scores of HAM-D and don't have more syndromic diagnosis of the disorder. The cognitive assessment of executive function consisted of the following tests: the DB test to evaluate the mental flexibility; the Stroop Test, which, among other parameters, assesses distractibility and response inhibition; the Shortened WCST, which is a measure of concept formation, abstraction, working memory, shifting set and the ability to utilize feedback; the Modified Six Elements Test, which accesses different components of executive functions. The results showed that at study entry patients have a moderate to severe score on HAM-D and prominent scores of executive dysfunction and apathy on Frontal Systems Behavior Scale (FrSBe), which evaluates apathy, disinhibition/emotional dysregulation and executive dysfunction. Furthermore, regarding the evaluation of cognitive executive functions the perseverative errors' scores in WCST-S were significant predictors of the HAM-D score in the follow-up group. However, this difference became nonsignificant after Benjamini-Hochberg correction $(\mathrm{p}=0.07)$. The perseverative errors' score from the Shortened WCST test also proved to be significant in predicting the score of the DSM-IV Social and Occupational Functioning Assessment Scale (SOFAS) at follow-up [41].

Another study was conducted with 28 patients diagnosed with MDD without comorbidities and a mean age of 35.03 years in two stages, in the acute state of MDD and after clinical recovery. In the first moment, these patients scored at least 24 in the HAM-D and the BDI tests. There was also a control group of 28 healthy subjects with no personal or first-degree family history of psychiatric disorders and mean age of 39.70 years. All subjects were assessed with the CANTAB test, and the executive function was assessed by ID/ED. The results showed impaired functioning in the number of stages $\mathrm{t}=-2.24 ; \mathrm{p}<0.05$ ), errors $\mathrm{t}=2.18 ; \mathrm{p}<0.05$ ), and trials $\mathrm{t}=2.21 ; \mathrm{p}<0.05$ in the ID/ED task in patients in the acute stage of MDD compared to healthy subjects. Changes in the HDRS scores $\mathrm{t}=7.64 ; \mathrm{p}<0.001$ and in the BDI $\mathrm{t}=5.09$; $\mathrm{p}<0.001$, indicate clinical recovery and, thus, a new analysis was performed with these patients. However, there were not significant differences between acute and remitted states regarding executive functions, which can mean a trait character of the disorder [42].

A study conducted only with men, focused to investigate the performance of patients with fully or partly remitted unipolar MDD without psychotic symptoms, compared to a control group. The group of patients consisted of 15 men with a mean age of 45.1 years, and a control group which also had 15 men, matched by age and IQ and a mean age of 42.1 years. The neuropsychological assessment of the executive functions was conducted through IGT, Go/No-Go Task and Delayed Alternation Task (DAT; 26). The results showed no significant differences in the IGT score between patients and the healthy control group. The ANOVA analysis between measures found a significant main effect of the factor block indicating a shift in drawing cards across blocks $\mathrm{F}(3,84)=16.33 ; \mathrm{p}=0.000$ but not an interaction between the factor block and the group $\mathrm{F}(3,84)=0.27 ; \mathrm{p}=0.844$. The authors also did not find significant differences between patients and controls in the Go/No-Go task and delayed alternation task, confirming the finding that these patients were unimpaired in the executive tasks associated with orbitofrontal function. However, the authors emphasize the limitations of the study, because of the small number of participants and exclusively male sample [43].

\section{DISCUSSION}

Depression, for its high rates of prevalence worldwide, has been widely studied in various aspects [44]. Studies of neuropsychological assessment have been conducted for a long time, but there are still many questions to be answered, among them the functioning of the executive functions in this disorder [45].

The neuropsychology approach aims to understand the correlation between behavioural and cognitive functioning and, how a deficit in this operation causes a particular symptom in neurological and non neurological disorders. In the case of psychiatric patients, in addition to clarifying the correlation symptom-cognitive functioning, it is also possible to measure the type and degree of impairment in specific disorders [45].

The executive functions have more than only one accepted definition, but it is known to be composed of several subcomponents, such as abilities of set-shifting, planning, inhibition, working memory and fluency, which are involved in controlling, integrating, organizing, inhibiting or even maintaining the functioning of other cognitive functions. Therefore, it becomes a centralizing function of cognitive functioning and deficits would impair personal, social, occupational and educational in the patient's 
life, affecting their activities of daily living [45]. Although many studies assess executive functions in patients with depression, the findings are not yet conclusive. Therefore, making a revision that uses the survey instruments, the specific findings and the specific population studied, allows a more detailed outline of what needs to be deepened in the area, despite the growth of publications on the subject.

The survey showed that out of the 28 articles selected, 25 found changes in some construct of executive functioning. But this impairment involved functioning findings based on different analyzes, such as severity of the disorder [14], partial executive alterations [30], melancholic subtype [31, $32,34]$, acute states of the disorder [39], among others. Thus, although the deficits appear in most articles, it does not mean uniformity of the findings.

One of the questions discussed by several studies was to whether cognitive changes in depression are belonging to acute conditions, and therefore have improved from the remission of symptoms, or if it would be a trait marker of the disorder and would remain so even after its remission. The authors suggest that an improved consistency of their findings would be possible with longitudinal studies, in contrast to the cross-sectional studies in order to avoid the possibility of the effect of any residual symptoms. So, the study should be long enough to ensure that there had been complete remission [14, 18, 27-30, 35, 36, 39, 40, 43].

Another important point is about the clinical heterogeneity of the disorder itself, which causes a difficulty in methodological studies. This is because besides the different possible subtypes (such as melancholic, non melancholic, psychotic for example), there is a high incidence of comorbidity and severity levels. Thus, the authors find it difficult to control all of these variables, which end up limiting the possibility of generalization of the findings. Furthermore, these patients are also medicated in most cases, which leads to doubt if there is a deficit found resulting from such therapy $[14,24,31,33,34,43]$. Some authors call attention to the fact that the studies have focused on melancholic and non melancholic subtypes, and it would be necessary to expand this to other subtypes [31, 33, 34]. It's not clear if this is a feature of depression, certain subtype specifics or of some other variable, such as level of severity and medication use.

It also has to be taken into consideration the difficulty in distinguishing patients with MDD and bipolar disorder. It can cause biased results, because literature has been evidenced the presence of executive deficits in bipolar patients $[46,47]$. The recent changing of the criteria from DSM-IV diagnoses to DSM-V re-opens the discussion of divisors between MDD and bipolar disorder. In this new criteria, the dysphoric symptoms (previously attributed to bipolar disorder), are now regarded as typical of the DDM as of Bipolar Disorder. We do not know if there are specific dysfunctions related to dysphoric components, because these until now were considered "tout-court" bipolar.

Studies to further investigate the findings in cognitive functions, in particular executive functions, have a clinical impact, since many of these patients do not respond to psychotherapies and pharmacotherapies. Could this difficulty in answering to treatments have its root in cognitive problems? Does this patient develop clinically or have difficulty planning, problem solving and flexibility? Is that a functional and executive problem before a symptom clinic?

\section{CONCLUSION}

In this review, the majority of studies found alterations in some aspects of executive functioning in patients with depression. The importance of these studies is better understood by the cognitive profile of these patients and predicts possible outcomes of drug therapy and psychotherapy. Furthermore, it is important to clarify the relationship between performance on cognitive tests and the difficulties presented by these patients in their daily lives. One study emphasized the relationship between symptoms and cognitive performance, realizing that patients with depression took longer to complete the test, which meets the slow and attentional deficits characteristic of the disorder.

Another important point is the need to increase the sample of subjects and to try to control comorbidity, severity levels, and medications used. Furthermore, it is necessary to study different subtypes of the disorder, beyond the melancholic and non melancholic subtypes, which are more emphasized. Furthermore, longitudinal studies are recommended to understand if the deficits found are characteristic features of the disorder and therefore remain even after remission of the symptoms or if they manifest only in acute states.

\section{LIST OF ABBREVIATIONS}

\begin{tabular}{|c|c|c|}
\hline BDI & $=$ & Beck Depression Inventory \\
\hline BADS & $=$ & $\begin{array}{l}\text { Behavioral Assessment of the Dysexecutive } \\
\text { Syndrome Q }\end{array}$ \\
\hline CANTAB & $=$ & $\begin{array}{l}\text { Cambridge Neuropsychological Test } \\
\text { Automated Battery }\end{array}$ \\
\hline COWAT & $=$ & Controlled Oral Word Association Test \\
\hline DAT & $=$ & Delayed Alternation Task \\
\hline DMS & $=$ & Delayed Matching to Sample Namely \\
\hline DB & $=$ & Digits Backward \\
\hline FrSBe & $=$ & Frontal Systems Behaviour Scale \\
\hline HAM-D & $=$ & Hamilton Depression Rating Scale \\
\hline $\mathrm{ID} / \mathrm{ED}$ & $=$ & Intradimensional/extradimensional \\
\hline IGT & $=$ & Iowa Gambling Task \\
\hline MDD & $=$ & Major Depressive Disorder \\
\hline PASAT & $=$ & Paced Auditory Serial Addition Test \\
\hline SPM & $=$ & Raven Standard Progressive Matrices \\
\hline SOFAS & $=$ & $\begin{array}{l}\text { Social and Occupational Functioning } \\
\text { Assessment Scale }\end{array}$ \\
\hline SWM & $=$ & Spatial Working Memory \\
\hline SOC & $=$ & Stockings of Cambridge task \\
\hline TOL & $=$ & Tower of London \\
\hline TMT B & $=$ & Trail Making Test Part B \\
\hline
\end{tabular}




\section{WMS-R $=$ Wechsler Memory Scale Revised \\ WSCT $=$ Wisconsin Card Sort Test}

\section{REFERENCES}

[1] Palazidou E. The neurobiology of depression. Br Med Bull 2012; 101: 127-45.

[2] Evans DL, Charney DS, Lewis L, et al. Mood disorders in the medically ill, scientific review and recommendations. Biol Psychiatry 2005; 58: 175-89

[3] Naismith SL, Norrie LM, Mowszowski L, Hickie IB. The neurobiology of depression in later-life, Clinical, neuropsychological, neuroimaging and pathophysiological features. Prog Neurobiol 2012; 98: 99-143.

[4] Fuster JM. The cognit: A network model of cortical representation. Intl J Psychophysiol 2006; 60: 125-32

[5] Austin MP, Mitchell P, Goodwin GM. Cognitive déficits in depression Possible implications for functional neuropathology. Br J Psychiatry 2001; 178: 200-6.

[6] Chepenik LG, Cornew LA, Farah MJ. The Influence of Sad Mood on Cognition. Emotion 2007; 7(4): 802-11.

[7] Stern RA, Prohaska ML. Neuropsychological Evaluation of Executive Functioning. Am Psychiatric Press Rev Psychiatry 1996; 15: 243-66.

[8] Luria AR. El cerebro en acción. $5^{\mathrm{a}}$ ed. Barcelona: Martínez Roca 1988; pp. 43-99.

[9] Luria A, Pribram KM, Homskaya ED. An experimental analysis of the behavioral disturbance produced by a left frontal arachnoidal endothelioma. Neuropsychologia 1964; 2: 257-80.

[10] Lezak MD. Relationship between personality disorders, social disturbances and physical disability following traumatic brain injury. J Head Trauma Rehabil 1987; 2: 57-69.

[11] Lezak MD. The problem of assesing executive functions. Intl $\mathrm{J}$ Psychol 1982; 17: 281-97.

[12] Ustárroz JT, Céspedes JMM, Valero CP. Funciones ejecutivas necesidad de una integración conceptual. Rev Neurol 2002; 34(7): 673-85.

[13] James IA, Reichelt FK, Carlsonn P, McAnaney A. Cognitive Behavior Therapy and Executive Functioning in Depression. J Cogn Psychother 2008; 22(3): 210-8.

[14] Paelecke-Habermann Y, Pohl J, Leplow B. Attention and executive functions in remitted major depression patients. J Affect Disord 2005; 89: 125-35.

[15] Grant MM, Thase ME, Sweeney JA. Cognitive Disturbance in outpatients depressed younger adults, evidence of modest impairment. Biol Psychiatry 2001; 50(1): 35-43.

[16] Gohier B, Ferracci L, Surguladze SA, et al. Cognitive inhibition and working memory in unipolar depression J Affect Disord 2009; 116: $100-5$.

[17] Nieuwenhuis S, Ridderinkhof KR, Blom J, Band GPH, Kok A. Error-related brain potentials are differentially related to awareness of response errors, Evidence from an antisaccade task. Psychophysiology 2001; 38(5): 752-60.

[18] Hammar A, Sorenser L, Ardal G, et al. Enduring cognitive dysfunction in unipolar major depression, A test-retest study using the Stroop paradigm. Scand J Psychol 2010; 51: 304-8.

[19] Lampe IK, Sitskoorn MM, Heeren TJ. Effects of recurrent major depressive disorder on behavior and cognitive function in female depressed patients. Psychiatry Res 2004; 125: 73-9.

[20] Schoenbaum G, Takahashi Y, Liu TL, McDannald MA. Does the orbitofrontal cortex signal value? Ann NY Acad Sci 2011; 1239(1): 87-99.

[21] Cella M, Dymond S, Cooper A. Impaired flexible decision-making in major depressive disorder. J Affect Disord 2010; 124: 207-10.

[22] Gualtieri CT, Johnson LG, Benedict KB. Neurocognition in Depression, Patients on and Off Medication Versus Healthy Comparison Subjects. J Neuropsychiatry Clin Neurosci 2006; 18(2): 217-25

[23] Porter RJ, Gallagher P, Thompson JM, Young AH. Neurocognitive impairment in drug-free patients with major depressive disorder. $\mathrm{Br}$ J Psychiatry 2003; 182: 214-20.

[24] Crews Jr WD, Harrison DW, Rhodes RD. Neuropsychological Test

Performances of Young Depressed Outpatient Women, An Examination of Executive Functions. Arch Clin Neuropsychol $1999 ; 14(6): 517-29$.
[25] Langenecker SA, Bieliauskas LA, Rapport LJ, et al. Face Emotion Perception and Executive Functioning Deficits in Depression. J Clin Exp Neuropsychol 2005; 27: 320-33.

[26] Mondal S, Sharma VK, Das S, et al. Neuro-cognitive functions in patients of Major Depression. Ind J Physiol Pharmacol 2007; 51(1): 69-75.

[27] Degl'Innocenti A, Agren H, Bäckman L. Executive deficits in major depression. Acta Psychiatr Scand 1998; 97: 182-8.

[28] Stordal KI, Lundervold AJ, Egeland J, et al. Impairment across executive functions in recurrent major depression. Nord $\mathrm{J}$ Psychiatry 2004; 58: 41-47.

[29] Stordal KI, Lundervold AJ, Biringer E, et al. Frequency and characteristics of recurrent major depressed patients with unimpaired executive functions. World J Biol Psychiatry 2005; 6(1): 36-44.

[30] Hammar A, Strand M, Ardal G, et al. Testing the cognitive effort hypothesis of cognitive impairment in major depression. Nord $\mathbf{J}$ Psychiatry 2011; 65: 74-80.

[31] Withall A, Harris LM, Cumming SR. A longitudinal study of cognitive function in melancholic and non-melancholic subtypes of Major Depressive Disorder. J Affect Disord 2010; 123: 150-7.

[32] Michopoulos I, Zervas IM, Papakosta VM, et al. Set shifting deficits in melancholic $v s$ non-melancholic depression, preliminary findings. Eur Psychiatry 2006; 21: 361-3.

[33] Markela-Lerenc J, Kaiser S, Fiedler P, et al. Stroop performance in depressive patients, A preliminary report. J Affect Disord 2006; 94 : 261-7.

[34] Quinn C, Harris A, Kemp A. The Interdependence of Subtype and Severity, Contributions of Clinical and Neuropsychological Features to Melancholia and Non-melancholia in an Outpatient Sample. J Int Neuropsychol Society 2012; 18: 361-9.

[35] Bhardwaj A, Wilkinson P, Srivastava C, Sharma M. Cognitive Deficits in Euthymic Patients with Recurrent Depression. J Nerv Ment Dis 2010; 198(7): 513-5.

[36] Yamamoto T, Shimada H. Cognitive Dysfunctions after Recovery from Major Depressive Episodes. Appl Neuropsychol Adult 2012; 19(3): 183-91.

[37] Preiss M, Kucerova H, Lukavsky J, et al. Cognitive deficits in the euthymic phase of unipolar depression. Psychiatry Res 2009; 169: 235-9.

[38] Hasselbalch BJ, Knorr U, Hasselbalch SG, et al. Cognitive Deficits in the Remitted State of Unipolar Depressive Disorder. Neuropsychology 2012; 26(5): 642-51.

[39] Reppermund S, Ising M, Lucae S, Zihl J. Cognitive impairment in unipolar depression is persistent and non-specific, further evidence for the final common pathway disorder hypothesis. Psychol Med 2009; 39: 603-14.

[40] Biringer E, Lundervold A, Stordal K, et al. Executive function improvement upon remission of recurrent unipolar depression. Eur Arch Psychiatry Clin Neurosci 2005; 255: 373-80.

[41] Withall A, Harris M, Cumming SR. The relationship between cognitive function and clinical and functional outcomes in major depressive disorder. Psychol Med 2009; 39: 393-402.

[42] Boeker H, Schulze J, Richter A, et al. Sustained Cognitive Impairments After Clinical Recovery of Severe Depression. J Nerv Ment Dis 2012; 200(9): 773-6.

[43] Westheide J, Wagner M, Quednow BB, et al. Neuropsychological performance in partly remitted unipolar depressive patients, focus on executive functioning. Eur Arch Psychiatry Clin Neurosci 2007; 257: 389-95.

[44] Maletic V, Robinson M, Oakes $\mathrm{T}$, et al. Neurobiology of depression, an integrated view of key findings. Int J Clin Pract 2007; 61(12): 2030-40.

[45] Stordal KI. A study of recurrent unipolar major depression and executive functions. The degree Doctor Medicinae (Dr. Med.),

Department of Clinical Medicine, Section of Psychiatry, University of Bergen: Norway 2006; pp. 3-92.

[46] Carta MG, Angst J. Epidemiological and clinical aspects of bipolar disorders, controversies or a common need to redefine the aims and methodological aspects of surveys. Clin Pract Epidemiol Ment Health 2005; 1(1): 4.

[47] Simonsen C, Sundet K, Vaskinn A, et al. Neurocognitive profiles in bipolar I and bipolar II disorder, differences in pattern and magnitude of dysfunction. Bipolar Disord 2008; 10(2): 245-55. 